Patients", Open Access Maced J Med Sci, 7(24), 4255-4259.

5. Anhua Long, Lihai Zhang and Yingze Zhang (2014), "Efficacy and safety of rivaroxaban versus low-molecular-weight heparin therapy in patients with lower limb fractures", ] Thromb Thrombolysis, 38(3), 299-305.

6. Hai-Feng Huang, Shan-Shan Li and XianTeng Yang (2018), "Rivaroxaban versus enoxaparin for the prevention of venous thromboembolism after total knee arthroplasty",
Medicine, 97(48), 13465.

7. Sean T Duggan (2012), "Rivaroxaban: a review of its use for the prophylaxis of venous thromboembolism after total hip or knee replacement surgery", Am J Cardiovasc Drugs, 12(1), 57-72.

8. Gomez-Outes A, Terleira-Fernandez AI and Suarez-Gea ML (2012), "Dabigatran, rivaroxaban, or apixaban versus enoxaparin for thromboprophylaxis after total hip or knee replacement: systematic review, meta-analysis, and indirect treatment comparisons", BMJ, 344.

\title{
NGHIÊN CỨU MộT Số YẾU TỐ LIÊN QUAN ĐẾN KIẾN THỨC VÀ THỰC HÀNH VỀ CHĂM SÓC SỨC KHỎE SINH SẢN CỦA PHỤ NỮ XÃ ĐẠI SƠN, HUYÊ̂N TỨ KỲ, TỈNH HẢI DƯƠNG
}

\section{TÓM TẮT}

Mục tiêu: tìm hiểu một số yếu tố có liên quan đến kiến thức và thực hành về chăm sóc sức khỏe sinh sản (CSSKSS) của phụ nữ xã Đại Sơn, huyện Tứ Kỳ, tỉnh Hải Dương. Đối tượng và phương pháp: phỏng vấn 384 phụ nữ tuổi 15-49 tuổi trong giai đoạn sinh sản. Kết quả: có mối liên quan giữa hoc vấn với kiến thức CSSKSS (OR=1,79; $p=0,01)$, giứa nghề nghiệp với kiến thức CSSKSS $(\mathrm{OR}=3,16 ; \mathrm{p}=0,02)$; giữa kiến thức về SKSS và thực hành $(O R=3,6 ; p<0,01)$, giữa tiếp cân dich vu với thực hành CSSKSS $(\mathrm{OR}=3,16$; $<<$ $0,01)$; giữa tuối kết hôn với thực hành CSSKSS (OR= $2,02 ; p=0,02)$; giữa nghề nghiêp với thực hành CSSKSS (OR=3,7; $p=0,03)$; giữa tuổi với thực hành CSSKSS (OR $=1,9 ; p=0,03)$. Kết luân: Kiến thức về SKSS, nghề nghiệp (công chức, viên chức), tuổi (3039), khả năng tiểp cập dịch vụ có liên quan đến kiến thức và thức hành SKSS ở phu nữ tuổi 15-49.

Tư khóa: sức khỏe sinh sản, kiến thức, thực hành

\section{SUMMARY}

FACTORS RELATED TO KNOWLEDGE AND PRACTICE OF REPRODUCTIVE HEALTH CARE OF WOMEN IN DAI SON COMMUNE, TU KY DISTRICT, HAI DUONG PROVINCE

Objectives: to find out the factors related to the knowledge and practice of women reproductive health care (RHC) in Dai Son commune, Tu Ky district, Hai Duong province. Subjects and methods: interviewing 384 women in the reproductive period aged 15-49 years old. Results: there is a correlation between education and $\mathrm{RH}$ knowledge $(\mathrm{OR}=1.79$; $\mathrm{p}$

*Trung tâm y tế Huyện Tứ Kỳ, tỉnh Hải Dương

**Bệnh viện Trung ương Quân đội 108

Chiu trách nhiệm chính: Bùi Thu Huyền

Email: buihuyendanso@gmail.com

Ngày nhân bài: 13.9.2021

Ngày phản biên khoa họ: 12.11.2021

Ngày duyệt bài: 24.11.2021

\author{
Bùi Thị Huyền*, Đỗ Văn Chiến**
}

$=0.01$ ), between occupation and RH knowledge (OR $=1.79 ; \mathrm{p}=0.01$ ), between knowledge and practice $(\mathrm{OR}=3,6 ; \mathrm{p}<0,01)$, between the access to RHC service and practice of RHC $(\mathrm{OR}=3.16 ; \mathrm{p}<0.01)$; between age of marriage and the practice of $\mathrm{RH}(\mathrm{OR}=2.02 ; \mathrm{p}=$ $0.02)$; between occupation and practice of RHC (OR= $3.7 ; p=0.03)$; between age RHC practice $(\mathrm{OR}=1.9$; $p=0.03)$. Conclusion: Knowledge of reproductive health, occupation (civil servant, public official), age (30-39), ability to access service are related to knowledge and practice RHC.

Keywords: reproductive health, knowledge, practice

\section{I. ĐẶT VẤN ĐỀ}

"Sức khỏe sinh sản là sự thoải mái hoàn toàn về thể chất, tinh thần và xã hội, không chỉ đơn thuần là không có bệnh, tật hoặc tàn phế của hệ thống sinh sản." [4]. Phụ nữ là cốt Iõi của sự phát triển kinh tế và xã hội. Sức khỏe và cuộc sống của họ có ý nghĩa quan trọng đối với bản thân, gia đình và cộng đồng. Hơn nữa, sức khỏe và đời sống của phụ nữ là yếu tố cớ bản cho thế hệ tương lai, phụ nữ nắm giữ chức năng của sự sống là sinh đẻ và nuôi dạy con cái [5]. Chúng ta vẫn chưa chú ý đầy đủ để đảm bảo rằng họ có thể thực hiện những việc này một cách an toàn [3].

Nội dung về chăm sóc sức khỏe sinh sản khá phong phú, tuy nhiên trong khuôn khổ đề tài này, chúng tôi chỉ đi sâu vào nghiên cứu một số yếu tố liên quan đến kiến thức và thực hành về kế hoạch hoá gia đình và làm mẹ an toàn của phụ nữ xã Đại Sơn, huyện Tứ Kỳ, Hải Dương là vùng nông thôn thuộc tỉnh Hải Dương, vùng Đồng bằng sông Hồng với điều kiện kinh tế, xã hội đang trên đà phát triển song còn có những khó khăn, bất cập về công tác y tế, chăm sóc sức khỏe, công tác Dân số - kế hoạch hóa gia đình. Để tìm hiểu một số yếu tố liên quan, yếu tố 
nào ảnh hưởng đến CSSKSS của phụ nữ xã Đại Sơn vẫn là câu hỏi còn để ngỏ. Vì vậy, tác giả đã tiến hành thực hiên nghiên cứu này với muc tiêu: Tìm hiểu một số yếu tố liên quan đến kiến thức và thực hành về chăm sóc sức khỏe sinh sản của đối tượng nghiên cứu.

\section{II. Đốl TƯợNG VÀ PHƯƠNG PHÁP NGHIÊN CỨU \\ Đối tượng nghiên cứu}

Tiêu chuẩn lựa chon: Phu nữ 15- 49 tuổi có chồng tại xã Đại Sơn, huyện Tứ Kỳ, tỉnh Hải Dương, tình nguyện tham gia nghiên cứu, có khả năng trả lời các câu hỏi phỏng vấn. Tiêu chuẩn loại trừ: Phụ nữ 15- 49 tuổi có chồng không đồng ý tham gia nghiên cứu, phụ nữ $15-49$ có chồng vắng mặt trong thời gian nghiên cứu, đi làm xa.

Địa điểm nghiên cứu: nghiên cứu được thực hiên tai xã Đại Sơnn, huyên Tứ Kỳ, tỉnh Hải Dương. Một vài đặc điểm về địa điểm nghiên cứu: xã có tổng diện tích đất tự nhiên là 9,74km² với 6 thôn, 2.849 hộ và 9.997 nhân khẩu, trong đó số phụ nữ 15 - 49 tuổi của xã là: 2.330 người $(23.3 \%)$, số phụ nữ 15- 49 có chồng là: 1.674 (16.7\%) (số liệu thống kê hết năm 2020)[1], [2].

Thời gian nghiên cứu: tháng 1 đến tháng 10/ 2021.

Thiết kế nghiên cứu: Áp dung phương pháp nghiên cứu của dịch tễ học với thiết lế nghiên cứu mô tả cắt ngang có phân tích

Cỡ mẫu: Cõ mẫu được tính theo công thức ước lượng 1 tỷ lệ trong nghiên cứu mô tả. Cõ mẫu tối thiều cần thiết được chọn trong nghiên cứu này là 384.

Phương pháp chọn mẫu: Sử dụng phương pháp chọn mẫu ngẫu nhiên hệ thống. Khung mẫu là danh sách phụ nữ 15-49 có chồng trong xã Đại Sơn theo Sổ theo dõi của Cộng tác viên Dân số các thôn bao gồm 1.674 người.

Phân tích và xử lý số liệu. Nhập và xử lý thông kê bằng phần mềm SPSS 20.0. Sử dụng phân tích tỷ suất chênh $\mathrm{OR}$ với khoảng tin cậy $95 \%$ (95\% CI). Mức ý nghĩa thống kê $\mathrm{p}<0.05$ được sử dụng để đánh giá mối liên quan có ý nghĩa trong thống kê có phân tích.

\section{KẾT QUẢ NGHIÊN CỨU}

Đăc điểm chung về đối tượng nghiên cứu Bảng 1. Phân bố đôî tượng nghiên cứu theo tuôi $(n=384)$

\begin{tabular}{|c|c|c|}
\hline Nhóm tuối & Số lượng & Tỷ lệ (\%) \\
\hline Dưới 20 tuối & 3 & 0,8 \\
\hline $20-29$ tuối & 63 & 16,4 \\
\hline $30-39$ tuối & 181 & 47,1 \\
\hline $40-49$ tuối & 137 & 35,7 \\
\hline Tống & $\mathbf{3 8 4}$ & $\mathbf{1 0 0}$ \\
\hline
\end{tabular}

Nhận xét: Phần lớn đối tượng tham gia nghiên cứu có tuổi từ 30 trở lên, trong đó nhóm chiếm tỷ lệ cao nhất là nhóm có tuổi từ $30-39$ (47,1\%). Đối tượng nghiên cứu dưới 20 tuổi chỉ chiếm $0,8 \%$.

Bảng 2. Phân bố đôi tượng nghiên cứu theo nghề nghiệp $(n=384)$

\begin{tabular}{|c|c|c|}
\hline Nghề nghiệp & Số lượng & Tỷ lệ (\%) \\
\hline Nông dân & 29 & 7,6 \\
\hline Công nhân & 280 & 72,9 \\
\hline Công chức/Viên chức & 33 & 8,6 \\
\hline Buôn bán & 40 & 10,4 \\
\hline Khác & 2 & 0,5 \\
\hline Tống & $\mathbf{3 8 4}$ & $\mathbf{1 0 0}$ \\
\hline
\end{tabular}

Nhận xét: Nghề nghiệp của đối tượng tập chung chủ yếu là đối tượng công nhân $(72,9 \%)$, bên canh đó còn có các nhóm đối tượng buôn bán $(10,4 \%)$, công chức/viên chức $(8,6 \%)$ và làm nông $(7,6 \%)$.

Bảng 3. Trinh độ học vấn của đôî tượng nghiên cứu $(n=384)$

\begin{tabular}{|c|c|c|}
\hline Trình độ học vấn & Số lượng & Tỷ lệ (\%) \\
\hline Tiếu học & 2 & 0,5 \\
\hline THCS & 200 & 52,1 \\
\hline THPT & 139 & 36,2 \\
\hline Trung cấp trở lên & 43 & 11,2 \\
\hline Tống & $\mathbf{3 8 4}$ & $\mathbf{1 0 0}$ \\
\hline
\end{tabular}

Nhân xét: Đối tượng nghiên cứu có trình đồ học vấn tốt nghiệp trung học cơ sở chiếm tỷ lẹ̉ cao nhất $(52,1 \%)$, có $11,2 \%$ đối tượng có học vấn từ trung cấp, cao đẳng trở lên.

Bảng 4. Phân bố đối tượng nghiên cứu theo tuối kêt hôn $(n=384)$

\begin{tabular}{|c|c|c|}
\hline Tuối kết hôn & Số lượng & Tỷ lệ (\%) \\
\hline Dưới 20 tuối & 48 & 12,5 \\
\hline $20-25$ tuốí & 321 & 83,6 \\
\hline Trên 25 tuối & 15 & 3,9 \\
\hline Tống & $\mathbf{3 8 4}$ & $\mathbf{1 0 0}$ \\
\hline
\end{tabular}

Nhânn xét: hầu hết đối tượng nghiên cứu kết hôn ở độ tuổi 20 đến 25 tuổi $(83,6 \%)$. Tỷ lệ đối tượng kểt hôn trước 20 chiếm 12,5\%.

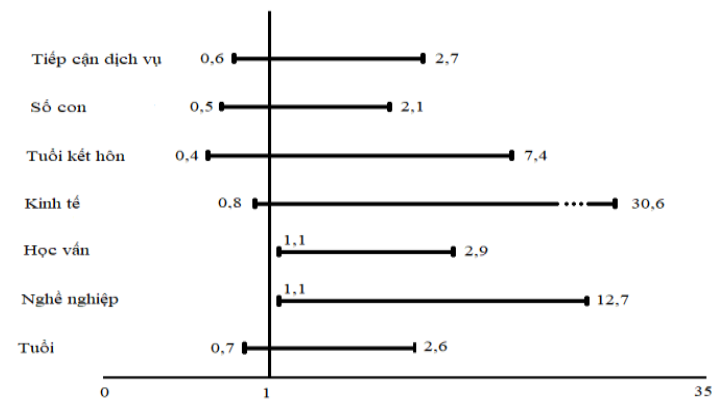

Biểu đồ 1. Một số yếu tố liên quan đến kiến thức chăm sóc SKSS của ĐTNC $(n=384)$

Nhận xét: có mối liên quan giữa học vấn của 
ĐTNC với kiến thức CSSKSS, OR= 1,79 (95\%CI: $1,1-2,9) ; p=0,01$. Và mối liên quan giữa nghề nghiệp của ĐTNC với kiến thức CSSKSS, OR= 3,16 (95\%CI: 1,1- 12,7; $p=0,02)$. Các mối liên quan này có ý nghĩa thống kê.

Bảng 5. Phân bố đối tượng nghiên cứu theo số con $(n=384)$

\begin{tabular}{|c|c|c|}
\hline Số con & Số lượng & Tỷ lệ (\%) \\
\hline Chưa có con & 2 & 0,5 \\
\hline Từ $1-2$ con & 326 & 84,9 \\
\hline 3 con trở lên & 56 & 14,6 \\
\hline Tống & $\mathbf{3 8 4}$ & $\mathbf{1 0 0}$ \\
\hline
\end{tabular}

Nhận xét: trong số đối tượng nghiên cứu chỉ có 2 đối tượng hiện chưa có con $(0,5 \%)$ và hầu hết đối tượng đã có từ $1-2$ con (84,9\%).

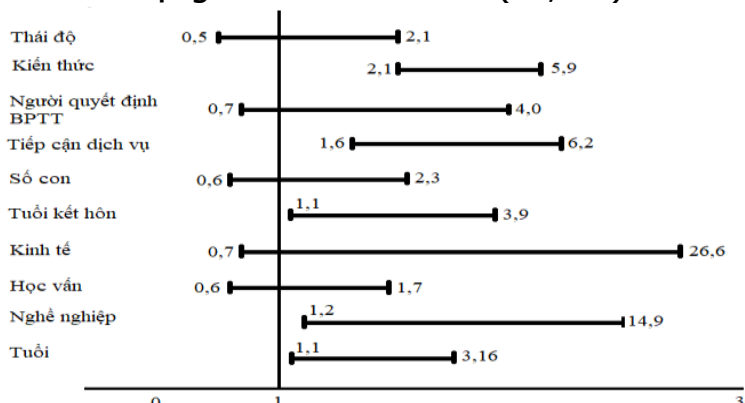

Biều đồ 2. Một số yếu tố liên quan đến thực hành chăm sóc SKSS của ĐTNC $(n=384)$

Nhận xét: có mối liên quan giữa nhận thức về CSSKSS với thực hành $(\mathrm{OR}=3,6)(95 \% \mathrm{CI}: 2,1$ - 5,9; p< 0,01), tiếp cận dịch vụ của ĐTNC với thực hành CSSKSS $(\mathrm{OR}=3,16(95 \% \mathrm{CI}: 1,6-$ $6,2) ; p<0,01)$, giữa tuổi kết hôn của ĐTNC với thực hành CSSKSS (OR= 2,02 (95\%CI:1,03-3,9; $\mathrm{p}=0,02)$, giữa nghề nghiệp của ĐTNC với thực hành CSSKSS (OR=3,7 (95\%CI: 1,2- 14,9), $p=$ $0,03)$, giữa tuối của ĐTNC với thực hành CSSKSS $(\mathrm{OR}=1,9(95 \% 1,1-3,16), \mathrm{p}=0,03)$.

\section{BÀN LUÂ̂N}

Về đặc điểm chung của nhóm phụ nữ tham gia nghiên cứu. Độ tuổi chủ yếu được điều tra là nhóm phụ nữ 15- 49, trong đó cao nhất là nhóm 30-39 tuổi $(47,1 \%)$ kết quả này tương đồng với nghiên cứu của Trần Thị Thắm (2010) [6]. Nhưng lại có sự khác nhau giữa nhóm thứ 2 trong nghiên cứu này, nhóm 40 - 49 tuổi (35.7\%), sau đó đến nhóm 20 -29 tuổi (chiếm $16,4 \%)$. Đối tượng tham gia nghiên cứu ở nhóm dưới 20 tuổi, chiếm tỷ lệ thấp nhất $(0,8 \%)$.

Nhóm đối tượng trình độ học vấn từ THCN trở lên chiếm $11,2 \%$, nhóm cao nhất là THCS (chiếm $52,1 \%$ ), xếp thứ 2 là nhóm THPT( $36,2 \%$ ) (bảng 3). So với nghiên cứu của Trần Thị Thắm( 2010), trình độ học vấn của đối tượng nghiên cứu còn hạn chế với 4\% có học vấn THCS, 29,3\% THPT, $18 \%$ Tiểu học, $7,7 \% \mathrm{THCN}$, và vẫn còn $4,0 \%$ phụ nữ không được đi học [6]. Có sự khác biệt này là do vị trí địa lý, điều kiện kinh tể văn hóa xã hội 2 nơi có sự khác nhau. Nghiên cứu này thực hiện tại địa phương đồng bằng Sông Hồng có kinh tế đang trên đà phát triển, còn nghiên cứu của Trân Thị Thắm (2010) là địa phương miên núi, kinh tế - xã hội còn nhiêu khó khăn [6]. Tuổi kết hôn của đối tượng nghiên cứu, kết hôn ở độ tuổi 20-25 chiếm 83,6\%, dưới 20 tuổi là 12,5\%, trên 25 tuổi chiếm 3,9\% (bảng 3.6).

Một số yếu tố liên quan đến kiến thức chăm sóc SKSS của đối tượng nghiên cứu. Kết quả nghiên cứu cho thây có mối liên quan giữa trình độ học vấn, nghề nghiệp với kiến thức về SKSS. Mối liển quan giữa đặc điểm nhân khẩu học với kiến thức về chăm sóc SKSS cho thấy, những người ở nhóm tuổi 30-39 có kiến thức tốt về chăm sóc SKSS cao gấp gấp 1,37 lần so với những người ở độ tuổi $\leq 29$ tuổi, điều này không có ý nghĩa thống kê với $p=0,3$. Điều này có nghĩa những người có trình độ học vấn cao thì chưa chắc đã có kiến thức về SKSS tốt hơn so với nhóm tuổi trình độ thấp hơn.

Mối liên quan giữa nghề nghiệp với kiến thức chăm sóc SKSS của đối tượng nghiên cứu, nhóm đối tượng là cán bộ, công chức, viên chức có kiến thức tốt về chăm sóc SKSS cao gấp 3,16 lần so với nhóm đối tượng công nhân, sự khác biệt có ý nghĩa thống kê với $\mathrm{p}=0,02$. Những đối tượng là cán bộ, công chức, viên chức có được kiển thức tốt hớn có thể do họ có điều kiện tiếp cận thông tin qua nhiều nguồn khác nhau, trong khi đó nhóm đối tượng là công nhân, kinh doanh buôn bán... do ảnh hưởng tính chất của công việc, họ chưa dành thời gian để tìm hiểu các kiến thức về chăm sóc SKSS. Đối tượng nghiên cứu có trình độ $\geq$ THPT có kiến thức chăm sóc SKSS cao hơn 1.79 lần nhóm có trình độ $\leq$ THCS. Cụ thể là các đối tượng có trình độ học vấn từ THCS trở lên thì tỷ lẹ có kiến thức đúng cao hơn so với đối tượng chỉ có học vấn tiểu học hoặc không đi học.

Một số yếu tố liên quan đến thực hành chăm sóc SKSS của đối tượng nghiên cứu. Cũng giống như mối liên quan với kiến thức SKSS, có mối liên quan giữa nhóm tuổi, nghề nghiệp, tuổi kết hôn với thực hành chăm sóc SKSS của ĐTNC. Có mối liên quan giữa tuổi với thực hành về chăm sóc SKSS. Nhóm đối tượng nghiên cứu ở độ tuổi 30-39 có thực hành tốt về SKSS cao gấp 1.9 lần so với nhóm tuổi $\leq 29$ và gấp 1.47 lần nhóm tuổi $\geq 40$ tuổi, điều này có ý nghĩa thống kê $p=0,03$. Lý giải về điều này, 
theo tôi là do phụ nữ ở nhóm tuổi 30-39 lúc này hầu như đã sinh đủ từ 1-2 con, con cái đã lớn hơn nên học có điều kiện quan tâm, chăm sóc sức khỏe nói chung và SKSS nói riêng nhiều hơn nên mức độ thực hành cao hơn.

Mối liên quan giữa nghề nghiệp với thực hành chăm sóc SKSS của ĐTNC Đối với công chức, viên chức có thực hành về chăm sóc SKSS cao gấp 3,7 lần nhóm công nhân, cao gấp 1,9 lần các nhóm khác. Có mối liên quan giữa tuổi kết hôn với thực hành về chăm sóc SKSS. Độ tuổi kết hôn từ 20-25 tuổi có thực hành tốt hơn 2,02 lần độ tuổi kết hôn dưới 20 tuổi, cao gấp 2,1 lần so với độ tuổi kết hôn trên 25 tuổi. Kết quả chỉ ra mối liên quan có ý nghĩa thống kê giữa khả năng tiếp cận dịch vụ chăm sóc SKSS và thực hành chăm sóc sức khỏe sinh sản của đối tượng nghiên cứu $(p<0,01)$. Đối tượng tiếp cận một cách tiện lợi có khả năng đạt thực hành cao hớn 3,16 lân đối tượng tiếp cận dịch vụ không tiện lợi.

\section{KẾT LUÂ̂N}

Qua nghiên cứu trên 384 phụ nữ trong giai đoan sinh đẻ tai xã Đai Sơn, huyên Tứ Kỳ, tỉnh Hải Dương chúng tôi thấy kiến thức về SKSS, nghề nghiệp (công chức, viên chức), tuổi (3039), khả năng tiếp cập dịch vụ là những yếu tố có liên quan đến thực hành CSSKSS tốt hơn so với các nhóm khác.

Kiến nghị. Cần nâng cao kiến thức đặc biệt là về SKSS, chuyển đổi nghề nghiệp và nâng cao chất lượng dịch vụ chăm sóc sức khỏe sinh sản cho phụ nữ vùng nông thôn.

\section{TÀI LIẸU THAM KHẢO}

1. Báo cáo chính tri số 17-BC/ĐU ngày 18/5/2020, trình Đại hội Đảng bộ xã Đại Sơn lần thứ nhất, nhiêm kỳ 20020- 2025.

2. Báo cáo thống kê DS - KHHGĐ năm 2020, số 56/BC- TTYT ngày 12/1/2021 của Trung tâm Y tế huyện Tứ Kỳ

3. Bộ Y tế (2001), Chiến lược Quốc gia về CSSKSS giai đoan 2001 - 2010, Hà Nôi.

4 . Bùi Thị Thu Hà (2008), Sức khỏe sinh sản, Nhà Xuất Bản Giáo Dú, Hà Nối.

5. Vương Tiến Hòa (2009), Sức khỏe sinh sản, Nhà Xuất Bản Y Hoc, Hà Nôii.

6. Trân Thi Thắm (2010), Kiến thức, thái độ, thực hành về chăm sóc sức khỏe sinh sản của phụ nữ có chồng trong đô tuổi sinh đẻ ( Qua nghiên cứu tại tỉnh Cao Bằng), Luận văn Thạc sỹ Xã hội học Đại học Khoa học xã hội và Nhẩn văn - Đại học quốc gia Hà Nội.

\section{KẾT QUẢ PHẪU THUÂT NộI SOI ĐIỀU TRI VIÊM PHÚC MAC RUỘT THỪA Ở TRẺ EM TẠI BÊ̂NH VIỆN NHI TRUNG ƯO'NG}

Lê Trung Hiếu ${ }^{1}$, Trần Anh Quỳnh ${ }^{2}$, Vũ Thị Hồng Anh ${ }^{1}$, Hoàng Hữu Kiên ${ }^{2}$, Nguyễn Thị Minh Huyền ${ }^{2}$

\section{TÓM TẮT}

Mục tiêu: Đánh giá kết quả điều trị viêm phúc mạc ruột thừa ở trẻ em bằng phẫu thuật nội soi tại bệnh viện Nhi Trung Ương. Phương pháp: Nghiển cứu mô tả, thiết kể cắt ngang. Gồm 95 bệnh nhân được phẫu thuật nội soi điêu trị viêm phúc mạc ruột thừa tại khoa Ngoại tổng hợp, bệnh viện Nhi Trung ương từ tháng 01/2021 đến tháng 06/2021. Kết quả: Tuổi phẫu thuật trung bình 7,37 \pm 3 tuổi; tỷ lệ nam/ nữ $\approx 1,5 ; 25,3 \%$ BN viêm phúc mạc khu trú, $7 \dot{4}, 7 \%$ viêm phúc mạc toàn thể. Ruột thừa ở hố châau phải $75,8 \%$ và $24,2 \%$ ở vị trí khác. Thời gian phẩu thuật trung bình $54,79 \pm 17,46$ phút. Thời gian nằm viện sau mổ trung bình $7,97 \pm 2,07$ ngày. Tỷ lệ biến chứng là 9,47\%. Kết luận: Phẫu thuật nội soi viêm phúc mạc

${ }^{1}$ Dại học y dược Thái Nguyên

²Bênh viện Nhi Trung Ương

Chiu trách nhiêm chính: Trần Anh Quỳnh

Email: tranquynh.nhp@gmail.com

Ngày nhận bài: 20.9.2021

Ngày phản biên khoa họ: 15.11.2021

Ngày duyệt bài: 24.11.2021 ruột thừa ở trẻ em là an toàn, hiệu quả và ít có biến chứng sau phẫu thuật.

Tư khóa: Viêm phúc mạc ruột thừa, phẫu thuật nội soi, trẻ em

\section{SUMMARY}

THE RESULTS OF LAPAROSCOPIC APPENDECTOMY FOR PERFORATED APPENDICITIS IN CHILDREN AT THE VIETNAM NATIONAL CHILDREN'S HOSPITAL

Objectives: To evaluate the results of laparoscopic appendectomy for perforated appendicitis in children at the Vietnam National Children's Hospital. Methods: Descriptive study, cross-sectional. Including 95 patients underwent laparoscopic appendectomy at the department of general surgery, National Hospital of Pediatrics since January 2021 to June 2021. Effective without any operative complications. Results: The mean age was $7,37 \pm 3$ years, male to female $\approx 1,5 ; 25,3 \%$ of the patients had localized and $74,7 \%$ generalized peritonitis. The appendix was in the right pelvic fossa in $75,8 \%$ and $24,2 \%$ in other position. The average operative time was $54,79 \pm 17,46$ mins. The average length of hospital 